\title{
FISIONOMIA E ORGANIZAÇÃO DA VEGETAÇÃO DO CARRASCO NO PLANALTO DA IBIAPABA, ESTADO DO CEARÁ ${ }^{1}$
}

\author{
Francisca Soares de Araújoº \\ Fernando Roberto Martins ${ }^{3}$
}

Recebido em 18/02/1998. Aceito em 17/12/1998

\begin{abstract}
RESUMO - (Fisionomia e organização da vegetação do carrasco no planalto da Ibiapaba, Estado do Ceará). O carrasco no planalto da Ibiapaba constitui formação vegetal própria? Para responder a essa questão, mediram-se a altura vertical (menos das trepadeiras) e o diâmetro basal (a partir de $3 \mathrm{~cm}$ ) do caule de plantas lenhosas e extraíram-se alíquotas de solo $(0-50 \mathrm{~cm}, 50-100 \mathrm{~cm}$ de profundidade) de 100 parcelas $(10 \times 10 \mathrm{~m})$ aleatórias em Jaburuna (354’34”S e 4059’24”W. altitudes em torno de $830 \mathrm{~m}$ ), município de Ubajara, Estado do Ceará. Dados de clima, solo, diâmetro, altura, densidade. área basal e fisionomia foram comparados com os levantados por outros autores em carrasco, caatinga e cerrado no nordeste. O carrasco ocorre sob precipitação anual média entre 668 e $1.289 \mathrm{~mm}$ e temperaturas entre 22 e $24^{\circ} \mathrm{C}$, sobre solo de Areias Quartzosas álicas, em altitudes entre 700 e $900 \mathrm{~m}$; tem densidade maior e área basal menor que a caatinga e o cerrado, diâmetros pequenos e similares, altura vertical média entre 3.7 e $5.4 \mathrm{~m}$. Difere da caatinga, do cerrado (e do cerradão) e da capoeira em vários aspectos do ecótopo, da organização e da físionomia, sendo formação vegetal própria. que pode ser caracterizada como fruticeto caducifólio alto, fechado, uniestratificado, com trepadeiras, dossel irregular e árvores emergentes esparsas.
\end{abstract}

Palavras-chaves - carrasco, fruticeto, organização, fisionomia, planalto da Ibiapaba

\begin{abstract}
Physiognomy and organization of the "carrasco" vegetation on the Ibiapaba plateau, Northeastern Brazil). Is the "carrasco" on the Ibiapaba plateau a unique plant formation? To answer this question the vertical height (except of climbers) and the stem basal diameter (from $3 \mathrm{~cm}$ on) of woody plants were measured, and soil extracts $(0-50$ and $50-100 \mathrm{~cm}$ depth) were taken from 100 random plots (10x $10 \mathrm{~m})$ at Jaburuna (3'54'34'S and 40 59'24'W, altitudes near $830 \mathrm{~m}$ ), municipality of Ubajara, Ceará State. Data on climate, soil, diameter, height, density, basal area, and physiognomy were compared with those surveyed by other researchers from the carrasco, caatinga, and cerrado in Northeastern Brazil. The carrasco occurs under an annual rainfall of between 668 and $1,289 \mathrm{~mm}$ and temperatures from 22 to $24^{\circ} \mathrm{C}$, on alic Quartz Sand soils, at altitudes between 700 and $900 \mathrm{~m}$; it has a larger density and a smaller basal area than the caatinga and the cerrado. small and similar diameters, and an average vertical height between 3.7 and $5.4 \mathrm{~m}$. It differs from the caatinga, cerrado (and cerradão) and secondary forest in many items of the ecotope, organization and physiognomy, thus being a unique plant formation, which can be characterized as a deciduous, high, closed, and unistratified shrubland intermingled by lianas, with an irregular canopy and sparse. emergent trees.
\end{abstract}

Key words - carrasco, shrubland, organization, physiognomy, Ibiapaba plateau

\footnotetext{
1. Parte da Tese de Doutorado do primeiro Autor; auxílios parciais à pesquisa da Fundação O Boticário de Proteção à Natureza e Fundação Cearense de Amparo à Pesquisa

2 Departamento de Biologia, Centro de Ciências, UFC, Campus do Pici, Bloco 906. C. Postal 12191, CEP 60455-760, Fortaleza. CE. Brasil. Bolsa CAPES/PICD

Departamento de Botânica, Instituto de Biologia, UNICAMP. C. Postal 6109. CEP 13083-970, Campinas, SP, Brasil
} 


\section{Introdução}

Na região nordeste do Brasil predomina o clima semi-árido, mas o relevo, os solos e o próprio clima são muito variáveis. Em consequiência, ocorrem diferentes tipos de vegetação, com fisionomias e floras distintas. A maior parte da área semi-árida ocorre sobre o embasamento cristalino, formado por grande superfície de aplainamento entre 300 e $500 \mathrm{~m}$ de altitude (Sampaio 1995). Nessa superfície, ocorrem relevos residuais cristalinos e sedimentares elevados, na forma de planaltos e chapadas. Entre os relevos de maiores extensões, o planalto da Ibiapaba (uma cuesta com mergulho para oeste), a chapada do Araripe e o planalto da Borborema atingem $1.000 \mathrm{~m}$ de altitude e a Chapada da Diamantina alcança $1.200 \mathrm{~m}$. Sobre o embasamento cristalino, geralmente ocorrem solos rasos, argilosos e rochosos, classificados como Litossolos, Regossolos e Brunos Não-Cálcicos; nas áreas sedimentares, os solos são geralmente profundos, classificados como Latossolos, Podzólicos e Areias Quartzosas (Sampaio 1995).

$\mathrm{Na}$ área semi-árida, principalmente em baixas altitudes, a caatinga é a vegetação xerófila dominante, apresentando variações físionômicas e florísticas (Romariz 1974; Ferri 1980; AndradeLima 1981; Rizzini 1997). Conforme as variações fisiográficas e climáticas, a fisionomia da caatinga pode variar de arbórea a arbustiva, aberta ou densa, ocorrendo sobre diferentes tipos de solos, desde profundos e arenosos, com grande infilltração de água (nas áreas sedimentares), até solos rasos, com pouca infiltração de água (nas áreas cristalinas). O condicionante principal daquela vegetação é a precipitação pluviométrica, estando a área da caatinga limitada pela isoieta máxima de $1.000 \mathrm{~mm}$, ocorrendo as caatingas mais xerófilas em isoietas pouco abaixo de $500 \mathrm{~mm}$ (Andrade-Lima 1981).

Sobre os planaltos e chapadas mais elevados do interior nordestino, há outros tipos de vegetação que podem ser confundidos com a caatinga. Andrade-Lima (1978) referiu-se a um tipo vegetacional xerófilo, denominado "carrasco" ou "catanduva," em que predominam formas subarbóreas e arbóreas de pequeno porte (3-4m), em solos arenosos das chapadas da bacia do rio Parnaíba, no Piauí. Andrade-Lima (1978) distinguiu fisionomicamente o carrasco da caatinga pela alta densidade dos indivíduos lenhosos, que apresentam troncos finos e são uniestratificados, e pela quase ausência de cactáceas e bromeliáceas. Segundo aquele autor, tal vegetação também apareceria na região do município de Barreiras (Bahia ocidental), onde é chamado de "grameal."

O termo carrasco tem sido usado em todo o Brasil para designar diferentes tipos de vegetação. No nordeste, inclui áreas de cerrado denso na Bahia, caatingas arbustivas sobre solos pedregosos e uma vegetação arbustiva densa xerófila no planalto da Ibiapaba e na chapada do Araripe. Figueiredo (1986) considerou o carrasco, no planalto da Ibiapaba e na chapada do Araripe, como um tipo próprio de vegetação, que, em sua flora, apresentaria algumas espécies de caatinga, cerrado e floresta. Fernandes (1990) e Fernandes \& Bezerra (1990) afirmaram ser aquela vegetação procedente da degradação parcial do cerradão, assumindo o aspecto de capoeira densa. Aqueles autores não esclareceram se o carrasco seria proveniente de degradação natural do cerradão, devido a mudanças climáticas ao longo do tempo geológico, ou se sua degradação seria devida à perturbação antrópica.

O cerrado ocorre desde o nível do mar até $1.300 \mathrm{~m}$ de altitude no planalto central brasileiro, sob precipitação pluvial em torno de $1.500 \mathrm{~mm}$ anuais, podendo ser menor que $800 \mathrm{~mm}$ no nordeste e maior que $2.000 \mathrm{~mm}$ no noroeste (Furley \& Ratter 1988). Os solos predominantes são Latossolos (46\%), Areias Quartzosas (15,2\%), Podzólicos (15,1\%), Litólicos $(7,3 \%)$, Lateritas Hidromórficas ou Plintossolos (6\%), Cambissolos (3\%), Concrecionários $(2,8 \%)$, Glei $(2 \%)$, Terras Roxas (1,7\%) e outros $(0,9 \%)$ (Goedert 1986).

A fisionomia do cerradão é de floresta escleromorfa fechada, ocorrendo em solos mais férteis (Furley \& Ratter 1988). O cerradão tem fisionomia florestal (Rizzini 1997) e os diferentes níveis de degradação da floresta, em ordem crescente de perturbação, foram chamados, por Löfgren (1898) e Eiten (1970), de capoeirão, capoeira, carrascal 
e campo. A capoeira seria um escrube (Eiten 1970) secundário, alto e fechado, ou uma floresta baixa secundária, com arvoretas (5-6m de altura) de poucas espécies e estrato herbáceo pouco desenvolvido (Klein 1980). Poucos e bem definidos estratos, diâmetros pequenos e abundância de trepadeiras herbáceas de poucas espécies, em florestas tropicais, são alguns indicativos de estádios iniciais de sucessão secundárias (Budowski 1963). Não há registro bibliográfico da presença ou abundância de trepadeiras no cerrado ou na caatinga.

Se o carrasco for um cerradão degradado, espera-se que ocorra em solos característicos das áreas de cerradão, apresente fisionomia de capoeira ou de cerrado aberto e flora empobrecida de cerradão. A fisionomia de cerrado aberto é resultante da degradação do cerradão através do fogo (Furley \& Ratter 1988). Se o carrasco for um tipo de caatinga, espera-se que ocorra em solos característicos das áreas de caatinga e apresente fisionomia e flora semelhantes a algum tipo de caatinga. Por outro lado, se o carrasco for formação vegetal individualizada, espera-se que difira da caatinga e do cerradão pela fisionomia, organização e flora.

A fisionomia refere-se à aparência geral externa da vegetação e a organização refere-se à disposição, arranjo, ordem e relações entre as partes (indivíduos ou espécies) que constituem o todo, isto é, a comunidade ou vegetação (Martins 1990). Sendo ambas atributos da forma da comunidade (Martins 1990), fisionomia e organização estão estreitamente relacionadas, a variação de uma causando variação na outra. Além da fisionomia e da organização, também a flora é importante para caracterizar a vegetação (Rizzini 1997). O conhecimento desses atributos pode permitir inferir sobre a amplitude da variação físionômica de certa vegetação, sua origem e suas relações com outros tipos de vegetação.

Comparando a flora lenhosa do carrasco no planalto sul da Ibiapaba, da caatinga e do cerrado no nordeste, Araújo et al. (1998a) não conseguiram definir se o carrasco seria um tipo de caatinga ou cerrado. Mas, através da análise de agrupamento a partir de matriz de presença ou ausência de espécies lenhosas em amostras de caatinga e carrasco, Araújo et al. (1998b) puderam concluir que o carrasco do planalto sul da Ibiapaba não seria um tipo de caatinga.

Este trabalho visa descrever a organização e a fisionomia da vegetação do carrasco e suas variações no planalto da Ibiapaba. A comparação de dados da organização e da fitofisionomia do carrasco no norte do planalto da Ibiapaba com os levantados por outros autores em outras áreas de carrasco possibilitará discutir sua variação no espaço, de modo a permitir propor uma classificação fitogeográfica mais adequada para o carrasco. Sua comparação com dados de organização e fisionomia, levantados na caatinga e no cerrado por outros autores, permitirá caracterizar essa vegetação em relação a esses outros tipos vegetacionais ocorrentes no nordeste. Não só a comparação da organização e da fisionomia de um tipo de vegetação com outros tipos vegetacionais é importante para sua caracterização, mas também a comparação dos ambientes (ecótopos) onde esses diferentes tipos de vegetação ocorrem. Assim, a comparação do ambiente em que o carrasco ocorre, considerando a posição no relevo, o clima e o solo, com o ambiente onde ocorrem a caatinga e o cerrado no nordeste do Brasil poderá evidenciar condicionantes peculiares da vegetação de carrasco. O conhecimento daí advindo contribuirá para caracterizar o ecótopo, a fisionomia e a organização e detectar prováveis padrões de variação espacial da vegetação do carrasco. A caracterização da físionomia, da organização e do ecótopo da vegetação do carrasco permitirá conceituar mais objetivamente esse tipo de vegetação, ainda pouco conhecido, do nordeste do Brasil.

\section{Material e métodos}

Área de estudo - A área estudada situa-se ao redor das coordenadas $3^{\circ} 54^{\prime} 34^{\prime \prime} S$ e $40^{\circ} 59^{\prime} 24^{\prime \prime} \mathrm{W}$, em altitudes em torno de $830 \mathrm{~m}$, na localidade de Jaburuna, município de Ubajara, no planalto norte da Ibiapaba, na divisa entre os Estados do Ceará e Piauí (Fig. 1). Os solos são Areias Quartzosas distróficas profundas, originadas de arenitos da Formação Serra Grande 
(SUDEC 1980). São muito friáveis, mesmo úmidos, não plásticos e não pegajosos. Têm textura arenosa, são excessivamente drenados, a capacidade de retenção de água é muito baixa e são extremamente ácidos. O horizonte A pode atingir até $30 \mathrm{~cm}$, com coloração bruno-escura, e o horizonte $\mathrm{C}$ é muito profundo, atingindo mais de $200 \mathrm{~cm}$, com coloração clara (SUDEC 1980). As temperaturas médias anuais variam pouco (22$24^{\circ} \mathrm{C}$ ) em todo o alto reverso imediato do planalto da Ibiapaba, no Estado do Ceará (Lins 1978). O município de Ubajara situa-se entre as isoietas de 1.000 e $1.200 \mathrm{~mm}$; as chuvas ocorrem no verãooutono, causadas pelos deslocamentos sazonais da Convergência Intertropical, concentrando-se a máxima precipitação em fevereiro, março e abril e chovendo apenas $1 \%$ do total anual em outros três meses do ano (Lins 1978).

Coleta de dados - Foi usado o método de parcelas (Müller-Dombois \& Ellenberg 1974), com dimensões de 10x10m, muito freqüente nos estudos quantitativos da caatinga (Gomes 1979; Fonseca 1991; Rodal 1992) e do carrasco (Araújo et al. 1998b). Foram alocadas aleatoriamente 100 parcelas, totalizando 1 ha. Para aleatorizar as parcelas, foram sorteados pares de números aleatórios num sistema de coordenadas com um eixo $\mathrm{Y}=400 \mathrm{~m}$ na direção $\mathrm{E}-\mathrm{W}$ e um eixo $\mathrm{X}=200 \mathrm{~m}$ na direção S-N. Foram incluídos todos os indivíduos lenhosos com diâmetro mínimo do caule no nível do solo de $3 \mathrm{~cm}$, vivos ou mortos ainda em pé. As trepadeiras lenhosas enraizadas no interior das parcelas também foram amostradas, por estarem entre as espécies de maior importância sociológica no carrasco estudado por Araújo et al. (1998b). Foram medidos o perímetro (com fita métrica) do caule no nível do solo e a altura vertical (com canos plásticos encaixáveis) do sistema aéreo das plantas dentro das parcelas, ou que tocaram por dentro ou por fora a linha de limite em dois lados (os voltados para os eixos das coordenadas) da parcela. As plantas que tocaram por dentro ou por fora a linha de limite dos dois outros lados da parcela foram desprezadas. Não foram medidas as alturas das trepadeiras. Como hábitos foram considerados: a) árvores os indivíduos lenhosos auto-sustentantes com um único caule e uma única copa limitada na parte terminal do caule; b) arbustos os indivíduos lenhosos auto-sustentantes com caule múltiplo ou ramificado abaixo de $50 \mathrm{~cm}$ e sem copa bem delimitada; e c) trepadeiras os indivíduos lenhosos sem capacidade de auto-sustentação, que se apoiavam e ou se enroscavam em suportes. No centro de cada parcela foi retirada uma alíquota de solo das profundidades de $0-50 \mathrm{~cm}$ (horizonte A e parte do C) e $50-100 \mathrm{~cm}$ (horizonte C). As análises físicas e químicas do solo foram realizadas no Departamento de Ciências do Solo da Universidade Federal do Ceará, de acordo com EMBRAPA (1979).

Organização da vegetação - Os termos organização, arquitetura e estrutura são semelhantes no sentido de referirem-se à maneira como os elementos que compõem um todo se arranjam, se ordenam e se relacionam (Ferreira s.d.). Vários autores consideram que a comunidade não é um amontoado caótico de indivíduos, mas sim um nível de organização biótica erigido a partir de regras de montagem (assembly rules, Drake 1990; Crawley 1997; Weiher \& Keddy 1995; Weiher et al. 1998). Autores europeus, em especial, reconhecem que arquitetura e estrutura são dois níveis hierárquicos no estudo da vegetação (Hallé et al. 1978; Oldeman 1979; 1991; UNESCO 1979; Vester \& Cleef 1998). A arquitetura refere-se à forma geral sintética, ao conjunto de relações das dimensões entre as partes que constituem um todo, sem que seja necessário dividí-lo em suas partes constitutivas (UNESCO 1979). No nível individual, a arquitetura significa a maneira como o corpo da planta é construído, isto é, a seqüência de desenvolvimento dos diferentes eixos do corpo da planta, seu arranjo no espaço e suas relações (Bell 1991). No nível da comunidade, o arranjo espacial das plantas, o número ou cobertura total das plantas por unidade de área, a distribuição de tamanhos entre os indivíduos, a distribuição das ecounidades (Oldeman 1991) no espaço são exemplos de descritores da arquitetura (Martins 1990). A estrutura refere-se à abundância das partes que compõem um todo, seu arranjo e suas relações no espaço e no tempo (UNESCO 1979). $\mathrm{Na}$ comunidade, a estrutura refere-se a cada um 
de seus componentes, sejam eles classificados como espécies, formas de vida, guildas, etc. Geralmente se reconhece que a comunidade vegetal apresenta estrutura espacial (estrutura vertical, estrutura horizontal e estrutura quan- titativa) e estrutura temporal dinâmica (Shimwell 1971). No presente estudo, as análises foram feitas apenas no nível de arquitetura, sem considerar as espécies e considerando a área basal, a densidade, o diâmetro e a altura dos indivíduos lenhosos.

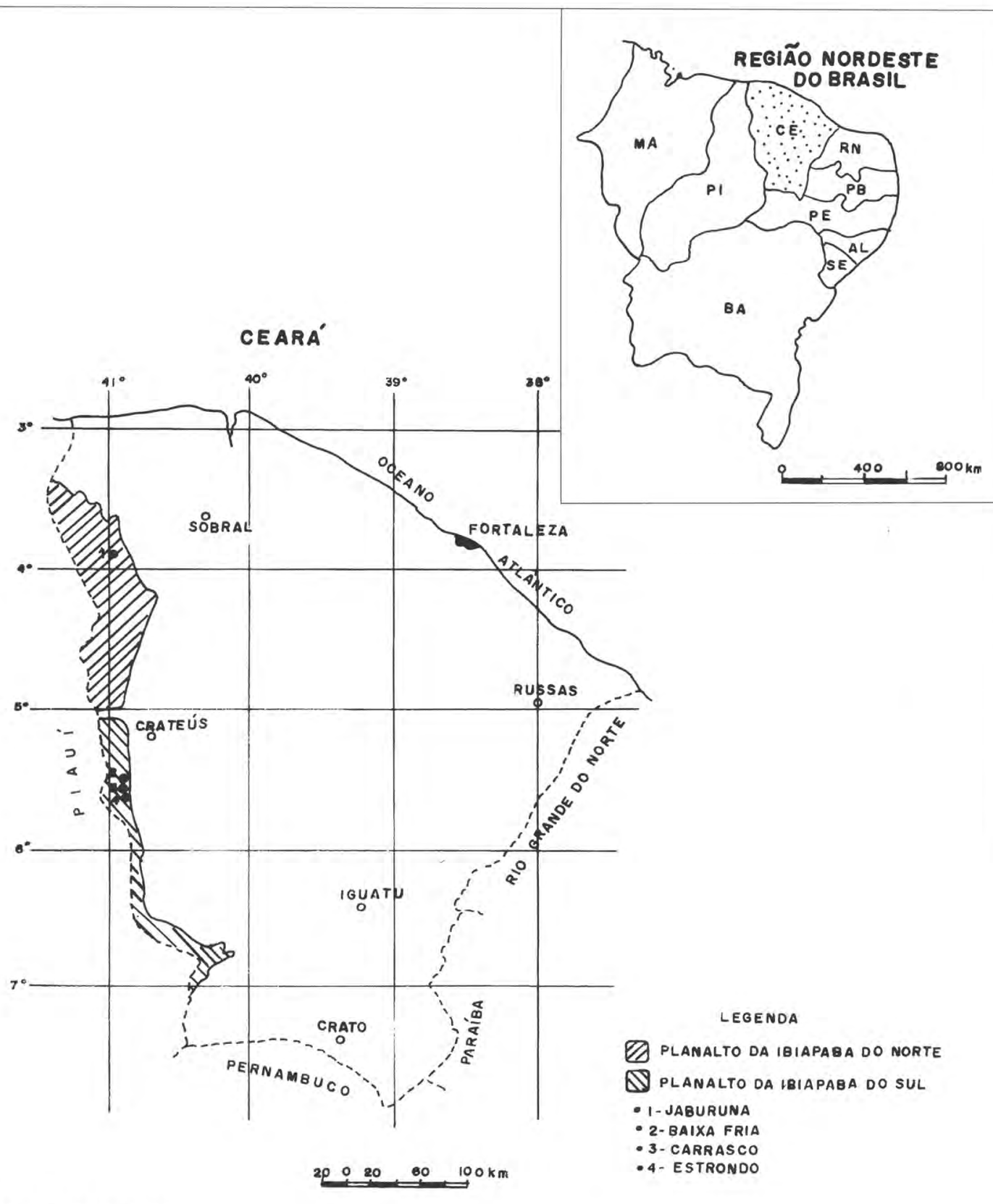

FONTE : SOUZA (1988)

Figura 1. Localização das áreas de carrasco no planalto da Ibiapaba, Estado do Ceará 
Estimativa dos parâmetros e comparação dos dados - Os parâmetros densidade média e área basal média por parcela de $100 \mathrm{~m}^{2}$ foram calculados através do programa FITOPAC (Shepherd 1995). Calculou-se o parâmetro altura média vertical por planta, excluídas as trepadeiras, através de média aritmética simples, somando-se todas as alturas verticais individuais e dividindose a soma pelo total de indivíduos. Araújo (1992) usou 25 parcelas de $10 \times 10 \mathrm{~m}$ na vegetação de carrasco em cada uma das localidades de Baixa Fria, Carrasco e Estrondo, no município de Novo Oriente, no planalto sul da Ibiapaba (Fig. 1), Estado do Ceará, para amostrar indivíduos lenhosos, incluindo trepadeiras, com diâmetro do caule no nível do solo a partir de $3 \mathrm{~cm}$ (Araújo et al. 1998b). Como o critério de inclusão dos indivíduos na amostra, o tamanho das parcelas, o procedimento de coleta de dados e o algoritmo de cálculo dos parâmetros foram os mesmos usados neste presente estudo, fez-se a comparação dos parâmetros estimados neste estudo com os estimados por Araújo et al. (1998b). A comparação foi feita através de um teste a priori de análise de variância (ANOVA), sendo testada $a$ posteriori a significância das diferenças entre as médias pelo teste de Scheffé (Zar 1984), usando o programa SYSTAT (Wilkinison 1992). Para normalizar os dados, foi feita a tranformação logarítimica; a posteriori, foi testada a normalidade através do teste $\mathrm{k} 2 \mathrm{e}$ a homocedasticidade das variâncias através do teste de Barttlett $\left(X^{2} 0,05\right.$, 3) (Zar 1984). A densidade e a área basal por parcelas $(\mathrm{N}=175)$ apresentaram distribuição normal e variâncias homogêneas, com coeficientes de variação $(\mathrm{CV})$ de 0,082 e 0,221 , respectivamente. As alturas individuais $(\mathrm{N}=8188)$ não apresentaram distribuição normal e nem variâncias homogêneas, com $\mathrm{CV}=0,284$, mas considerando que o $\mathrm{N}$ é muito grande e que a ANOVA é um teste robusto, optou-se por usar essa análise também para testar diferença de altura média entre amostras diferentes de carrasco. A distribuição de diâmetro, com intervalos de $3 \mathrm{~cm}$ fechados à esquerda e abertos à direita, foi feita através do programa DIAMFITO, desenvolvido pelo Dr. Luiz Pacheco Motta, do Departamento de Biologia
Vegetal da Universidade Federal de Viçosa, Estado de Minas Gerais. A distribuição de altura foi analisada através de um diagrama de rol, em que o eixo $\mathrm{X}$ representa a seqüência de indivíduos do menor para o de maior altura, e o eixo $\mathrm{Y}$ informa o valor de cada altura. O diagrama de rol é muito adequado para evidenciar a estratificação da vegetação. Se um segmento relativamente grande da curva tende a ficar paralelo ao eixo $\mathrm{X}$, indica número relativamente grande de indivíduos com alturas semelhantes, que constituiriam um estrato da vegetação. Uma curva com mais de um patamar relativamente longo indicaria a existência de mais de um estrato na vegetação. Se, ao contrário, a curva é bem inclinada ou com muitos patamares curtos, indicaria que os indivíduos têm alturas bem diferentes e não constituiriam um estrato característico. Sobre o diagrama de rol foi traçada a distribuição de freqüência, considerando intervalos de $1 \mathrm{~m}$ no eixo $\mathrm{Y}$, na qual o comprimento de cada segmento projetado no eixo $\mathrm{X}$ é diretamente proporcional à freqüência absoluta da respectiva classe. Para permitir comparar as quatro áreas de carrasco, usou-se a frequiência relativa de cada classe de altura. Os resultados das análises do solo e da arquitetura da vegetação foram comparados qualitativamente com os obtidos a partir de levantamentos de cerrados e caatingas no nordeste do Brasil que usaram critérios e procedimentos semelhantes.

\section{Resultados e discussão}

Clima - Embora a temperatura não apresente grandes variações espaciais, a precipitação varia muito de um local a outro no planalto da Ibiapaba. A precipitação média anual no posto de Tianguá, situado na transição floresta/carrasco, distando aproximadamente $20 \mathrm{~km}$ em linha reta da área estudada em Jaburuna, é de cerca de $1.289 \mathrm{~mm}$ (FUNCEME 1995), embora essa área esteja mapeada entre as isoietas de 1.000 e $1.200 \mathrm{~mm}$ (Lins 1978). Porém, ainda no planalto norte da Ibiapaba, outras áreas com vegetação de carrasco, mais distantes de Jaburuna, apresentam valores bem menores de precipitação, como $668 \mathrm{~mm} \mathrm{em}$ Carnaubal (FUNCEME 1995) ou $676 \mathrm{~mm} \mathrm{em}$ Poranga (SUDENE 1990). No planalto sul da 
Ibiapaba, no município de Alívio, o mais próximo das localidades estudadas por Araújo et al. (1998b), a precipitação anual média é de $838 \mathrm{~mm}$ (SUDENE 1990). Assim, a vegetação de carrasco ocorre sob precipitação anual média que varia de 668 a $1289 \mathrm{~mm}$, indicando que o total pluviométrico não parece ser importante no condicionamento de sua ocorrência. Caatingas arbóreas podem ocorrer sob precipitação máxima de até $1.000 \mathrm{~mm} / \mathrm{ano}$ (Andrade-Lima 1981). Os cerrados também podem ocorrer no nordeste sob totais pluviométricos anuais médios ligeiramente inferiores a 800mm (Furley \& Ratter 1988). Portanto, a precipitação pluviométrica média anual não distingue se a aridez no carrasco é maior ou menor que na caatinga ou no cerrado, no nordeste do Brasil. Porém, o cerrado é muito mais ligado a fatores de natureza edáfica que climática, enquanto a caatinga sofre forte influência do clima (Reis 1976). O mergulho das camadas no reverso do planalto de Ibiapaba (trata-se de uma cuesta) pode ocasionar fluxo lateral de água profunda no solo para oeste, onde se situa o carrasco, ocorrendo, provavelmente, maior disponibilidade de água profunda no solo do carrasco que no da caatinga. A precipitação pluvial parece não diferir da ocorrente na caatinga e no cerrado, mas o provável fluxo lateral de água profunda no solo e a diminuição da temperatura em função da maior altitude podem tornar o ambiente do carrasco menos árido que o da caatinga.

Solo - O solo do carrasco em Jaburuna é distrófico (saturação de bases menor que 50\%), endoálico (saturação de alumínio maior que $50 \%$ entre 50 e $100 \mathrm{~cm}$ ), com baixa capacidade de troca cationnica ( $\mathrm{T}$ ) e valores de $\mathrm{pH}$ muito baixos (Tab. 1). Os teores de nutrientes ( $\mathrm{Ca}, \mathrm{Mg}, \mathrm{K}, \mathrm{P}$ ), carbono, matéria orgânica e nitrogênio foram muito baixos e diminuíram com a profundidade. $\mathrm{O}$ pH médio foi semelhante entre as profundidades. Os valores das outras variáveis analisadas também diminuíram com a profundidade, enquanto os teores de $\mathrm{Al}^{3+}$ aumentaram. A textura variou de areia a areia franca (Tab. 1). As percentagens médias de areia grossa diminuíram com a profundidade, enquanto as de areia fina, silte e argila aumen- taram. Esses resultados foram semelhantes aos encontrados nas Areias Quartzosas distróficas estudadas em outros locais do nordeste (Jacomine et al. 1973; 1979) e aos encontrados por Araújo (1992) nas amostras de carrasco no planalto sul da Ibiapaba.

Nos Estados de Pernambuco e Bahia, as Areias Quatzosas distróficas profundas têm origem sedimentar na Série Cipó. Nos locais de sua ocorrência naqueles Estados, a precipitação pluvial anual média varia em torno de $500 \mathrm{~mm}$ e ocorre uma caatinga baixa, de 4 a $7 \mathrm{~m}$ de altura (Andrade-Lima 1981). Nos Estados do Ceará e Piauí, também foi observada a ocorrência de caatinga sobre Areias Quartzosas em baixa altitudes, onde a espécie dominante é Piptadenia moniliformis Benth. (Mimosaceae). Tais caatingas foram chamadas de caatingas arenícolas (Rodal 1992), porém as paisagens mais típicas da caatinga ocorrem em terrenos cristalinos (Fernandes 1982), onde predominam solos rasos, argilosos e rochosos (Sampaio 1995). As Areias Quartzosas ocupam $15,2 \%$ da área do cerrado no Brasil, predominando no nordeste e sudeste de Goiás, norte de Minas Gerais, sul do Maranhão, norte e sul do Piauí, sudeste e sudoeste de Mato Grosso, norte de Mato Grosso do Sul, oeste da Bahia e Rondônia (Goedert 1986). Porém, o cerradão ocorre em solos mais férteis, com maiores teores de cálcío nas camadas superficiais, que os solos das outras fisionomias do cerrado e está freqüentemente associado a áreas marginais de florestas decíduas e semidecíduas (Furley \& Ratter 1988). Nos solos sob cerradão, a soma de bases varia de 0,20 a 8,70 meq $/ 100 \mathrm{~g}$ TFSA, o teor de $\mathrm{N}$ de 0,26 a $14 \%$ e o de $\mathrm{Al}^{3+}$, de 0 a 2,36 meq/100 g TFSA, com pH variando entre 4,5 e 6,0 (Furley \& Ratter 1988). Tais valores são maiores que os encontrados nas Areias Quartzosas do carrasco, exceto o $\mathrm{Al}^{3+}$, menor no cerradão. Os maiores teores de nutrientes, o pH mais alto e menores teores de $\mathrm{Al}^{3+}$ indicam que o solo do cerradão é mais fértil que o do carrasco. Além disso, o cerradão não ocorre, como regra, sobre Areia Quartzosa. O solo de Areia Quartzosa também ocorre sob a caatinga, mas esta geralmente ocorre em baixas altitudes, enquanto o carrasco ocorre entre 700 e $900 \mathrm{~m}$. A 
ocorrência da caatinga sobre Areia Quartzosa não é modal, a caatinga arenícola é considerada um tipo especial de caatinga, enquanto o carrasco no planalto da Ibiapaba parece ocorrer exclusivamente sobre Areia Quartzosa.

Densidade e área basal - No carrasco de Jaburuna, a densidade e a área basal foram de $4.480 \mathrm{ind} / \mathrm{ha}$ e $19,204 \mathrm{~m}^{2} / \mathrm{ha}$, respectivamente (Tab. 2). Dos 4.480 indivíduos amostrados, 226 (5\%) estavam mortos ainda em pé. Dos 4.254 indivíduos vivos, $3.425(80,8 \%)$ eram arbustos, $592(13,9 \%)$ árvores e $227(5,3 \%)$ trepadeiras, ocupando área basal de $13,60 \mathrm{~m}^{2} / \mathrm{ha}(70,8 \%)$, $5,19 \mathrm{~m}^{2} / \mathrm{ha}(27,0 \%)$ e $0,42 \mathrm{~m}^{2} /$ ha $(2,2 \%)$, respec- tivamente. Nas áreas do sul da Ibiapaba, 4\%, 2\% e 3,6\% dos indivíduos estavam mortos ainda em pé e as trepadeiras representaram $15 \%, 6,8 \%$ e $13,5 \%$ do indivíduos vivos, contribuindo com $1,67 \mathrm{~m}^{2} / \mathrm{ha}(11,4 \%), 0,62 \mathrm{~m}^{2} /$ ha $(2,3 \%)$ e $1,29 \mathrm{~m}^{2} /$ ha $(6,6 \%)$ da área basal total em Baixa Fria, Carrasco e Estrondo, respectivamente (Araújo et al. 1998b). Os arbustos também foram a forma de crescimento predominante no planalto sul da Ibiapaba (Araújo et al. 1998b). Em Jaburuna, durante a coleta de dados nas parcelas, observouse que a maior parte das trepadeiras apresentava caules finos, com diâmetro no nível do solo menor que $3 \mathrm{~cm}$. Assim, a menor percentagem do número e área basal de trepadeiras amostradas em

Talela 1. Variáveis físicas e químicas analisadas nas amostras do solo de Areias Quartzosas, coletadas em 100 parcelas, nas profundidades de 0 a 50 e de 50 a $100 \mathrm{~cm}$, na localidade de Jaburuna, município de Uhajara. CE. S (soma das bases), T (capacidade de troca de cátions). V (saturação de bases), m (percentagem de saturação de alumínio) e PST (percentagem de sódio trocável), dp (desvio padrão)

\begin{tabular}{|c|c|c|c|c|c|c|c|c|}
\hline \multirow{3}{*}{ Variáveis } & \multicolumn{8}{|c|}{ Profundidade $(\mathrm{cm})$} \\
\hline & \multicolumn{2}{|c|}{$0-50$} & \multicolumn{2}{|c|}{$50-100$} & \multicolumn{2}{|c|}{$0-50$} & \multicolumn{2}{|c|}{$50-100$} \\
\hline & média & $(\mathrm{dp})$ & média & $(d p)$ & máx & mín & máx & mín \\
\hline Areia Grossa (\%) & 58,290 & $(4,215)$ & 51.990 & $(3.639)$ & 66,00 & 44,000 & 62,00 & 42.000 \\
\hline Areia Fina $(\%)$ & 30,170 & $(3,490)$ & 32.280 & $(3.649)$ & 42,00 & 23,000 & 55,00 & 20.000 \\
\hline Silte $(\%)$ & 2,910 & $(1,450)$ & 4.060 & $(1.549)$ & 9.00 & 1,000 & 11.00 & 1.000 \\
\hline Argila $(\%)$ & 8.640 & $(1,987)$ & 11.850 & $(2.213)$ & 15,00 & 3,000 & 17,00 & 5,000 \\
\hline Argila Natural (\%) & 1,490 & $(0,904)$ & 2.520 & $(1.168)$ & 6,00 & 1,000 & 7,00 & 1.000 \\
\hline Grau de floculação & 82,130 & $(10,141)$ & 78.380 & $(10.244)$ & 92,00 & 44,000 & 93,00 & 46,000 \\
\hline Densidade global $\left(\mathrm{g} / \mathrm{cm}^{3}\right)$ & 1,421 & $(0,027)$ & 1.406 & $(0.029)$ & 1.50 & 1,350 & 1.49 & 1.330 \\
\hline Densidade de partículas $\left(\mathrm{g} / \mathrm{cm}^{3}\right)$ & 2,632 & $(0,055)$ & 2.630 & $(0.059)$ & 2,81 & 2,480 & 2,76 & 2.490 \\
\hline Umidade $1 / 3 \mathrm{~atm}(\%)$ & 4,686 & $(1,098)$ & 6.362 & $(1.630)$ & 9,30 & 2,600 & 10,10 & 3.300 \\
\hline Umidade $15 \mathrm{~atm}(\%)$ & 2.810 & $(0,414)$ & 3.568 & $(0.583)$ & 4.30 & 2,100 & 5,50 & 2,500 \\
\hline Água Útil (\%) & 1,817 & $(0,878)$ & 2.797 & $(1.309)$ & 5,00 & 0,100 & 6,00 & 0.600 \\
\hline $\mathrm{pH}$ Água & 3,959 & $(0,214)$ & 3.965 & $(0.149)$ & 4,60 & 3,000 & 4,60 & 3.700 \\
\hline $\mathrm{pH} \mathrm{KCL}$ & 3,699 & $(0,121)$ & 3.791 & $(0.126)$ & 4,10 & 3,400 & 4,10 & 3,500 \\
\hline Condutividade elétrica (dS/m) & 0,568 & $(0,220)$ & 0,314 & $(0.167)$ & 0,96 & 0,160 & 1,22 & 0.130 \\
\hline $\mathrm{Ca}^{2+}(\mathrm{mE} / 100 \mathrm{~g}$ de solo $)$ & 0.249 & $(0,106)$ & 0,153 & $(0.096)$ & 0,58 & 0,100 & 0,49 & 0,020 \\
\hline $\mathrm{Mg}^{2+}(\mathrm{mE} / \mathrm{l} 00 \mathrm{~g}$ de solo $)$ & 0,182 & $(0,171)$ & 0,092 & $(0.029)$ & 1,80 & 0,080 & 0,19 & 0,040 \\
\hline $\mathrm{K}^{+}(\mathrm{mE} / \mathrm{loOg}$ de solo $)$ & 0,074 & $(0,020)$ & 0,044 & $(0.017)$ & 0,13 & 0,030 & 0,10 & 0,020 \\
\hline $\mathrm{Na}^{+}(\mathrm{mE} / 100 \mathrm{~g}$ de solo $)$ & 0,050 & $(0,023)$ & 0.041 & $(0.018)$ & 0,12 & 0,020 & 0,13 & 0.020 \\
\hline $\mathrm{AI}^{3+}(\mathrm{mE} / 100 \mathrm{~g}$ de solo $)$ & 0,429 & $(0,080)$ & 0.525 & $(0.097)$ & 0.60 & 0,200 & 0,80 & 0.300 \\
\hline $\mathrm{H}^{+}+\mathrm{Al}^{3+}(\mathrm{mE} / \mathrm{l00g}$ de solo $)$ & 1.519 & $(0,252)$ & 1,387 & $(0,258)$ & 2,23 & 0,910 & 1,98 & 0,800 \\
\hline $\mathrm{S}(\mathrm{mE} / \mathrm{lo0g}$ de solo $)$ & 0.534 & $(0,140)$ & 0,326 & $(0,109)$ & 0,90 & 0,300 & 0,70 & 0,200 \\
\hline $\mathrm{T}\left(\mathrm{S}+\mathrm{H}^{+}+\mathrm{Al}^{3+}\right)$ & 2,052 & $(0,309)$ & 1.719 & $(0.292)$ & 2,81 & 1,500 & 2,28 & 1,000 \\
\hline $\mathrm{V}(\%)(100 \mathrm{~S} / \mathrm{T})$ & 26,140 & $(5,671)$ & 19,060 & $(5.367)$ & 43,00 & 15,000 & 33,00 & 10.000 \\
\hline $\mathrm{m}(\%)\left(100 \mathrm{AI}^{3+} / \mathrm{S}+\mathrm{AI}^{3+}\right)$ & 44,490 & $(9,249)$ & 61.780 & $(9.793)$ & 67,00 & 21,000 & 78,00 & 20,000 \\
\hline PST $(100 \mathrm{Na} / \mathrm{T})$ & 2.370 & $(1,125)$ & 2.400 & $(1.333)$ & 6,00 & 1,000 & 9,00 & 1.000 \\
\hline Carbono $(\%)$ & 0,445 & $(0,118)$ & 0.299 & $(0.090)$ & 0,69 & 0,190 & 0,53 & 0.100 \\
\hline Nitrogênio (\%) & 0.030 & $(0,006)$ & 0.024 & $(0.006)$ & 0.04 & 0,020 & 0,03 & 0.010 \\
\hline $\mathrm{C} / \mathrm{N}$ & 14,950 & $(2,709)$ & 12.240 & $(1.955)$ & 21,00 & 9,000 & 18,00 & 8.000 \\
\hline Matéria Orgânica (\%) & 0.766 & $(0,203)$ & 0.507 & $(0.156)$ & 1,19 & 0,330 & 0.91 & 0.170 \\
\hline Fósforo disponível (ppm) & 3,760 & $(1,026)$ & 1,580 & $(0.684)$ & 6,00 & 1,000 & 4,00 & 1,000 \\
\hline
\end{tabular}


Jaburuna em relação às outras três amostras decorreu do predomínio de trepadeiras com caules mais finos que o limite mínimo amostrável, e não de sua menor abundância na vegetação. A área basal das trepadeiras pode dar idéia da proporção de sua biomassa em relação à dos arbustos e árvores. Entretanto, as trepadeiras apresentam concentração de biomassa na copa muito maior que qualquer outra forma lenhosa (Bullock 1990). Assim, como a maior parte da biomassa das trepadeiras ocorre na copa e não no caule, a proporção de biomassa de trepadeiras no carrasco deve ser maior que a indicada pela área basal. Portanto, o carrasco é vegetação arbustiva com árvores esparsas e grande abundância de trepadeiras.

O carrasco em Jaburuna apresentou menor densidade total que as áreas de carrasco estudadas por Araújo et al. (1998b). A área basal foi semelhantes à encontrada em Estrondo, menor que a em Carrasco e maior que a em Baixa Fria. A altura média em Jaburuna foi menor que a do carrasco no planalto sul da Ibiapaba (Tab. 2). As três amostras de carrasco estudadas por Araújo et al. (1998b) apresentaram densidades de 5.952, 5.724 e $6.590 \mathrm{ind} / \mathrm{ha}$ e áreas basais de 14,2, 27,7 e $19,5 \mathrm{~m}^{2} /$ ha, respectivamente. Na caatinga, a densidade tem variado de 1.080 a $4.250 \mathrm{ind} / \mathrm{ha} e$ a área basal de 15,6 a 34,0m²/ha (Sampaio 1996). A variação da densidade e da área basal na caatinga pode estar associada à variação fisionômica (Rodal 1992).

O carrasco apresentou densidade total aparentemente maior que a caatinga, mas sua área basal foi menor, confirmando a maior densidade e a menor espessura do caule dos indivíduos lenhosos no carrasco em relação à caatinga. No cerrado nordestino, a densidade e a área basal têm variado de 320 a $3.590 \mathrm{ind} / \mathrm{ha}$ e de 11 a $49,5 \mathrm{~m}^{2} / \mathrm{ha}$ (Sampaio 1996). Tal amplitude de variação da densidade decorre da grande variação fisionômica do cerrado (Furley \& Ratter 1988). Embora aqueles valores tenham se baseado em apenas oito levantamentos de cerrado no nordeste (Sampaio 1996), o cerrado nordestino apresenta, aparentemente, densidade total menor e área basal total maior que o carrasco. A degradação do cerradão pode levar ao aparecimento de fisionomias mais abertas (Furley \& Ratter 1988) e não de uma capoeira e, se o carrasco fosse uma degradação do cerradão, então deveria apresentar menor densidade que o cerrado ou, pelo menos, semelhante à das fisionomias mais abertas do cerrado. O carrasco apresenta maior densidade de arbustos, árvores e trepadeiras que a caatinga e o cerrado.

A grande abundância de trepadeiras herbáceas de poucas espécies é um dos indicativos de estádios iniciais de sucessão secundária em florestas tropicais, enquanto a pequena abundância de trepadeiras lenhosas de muitas espécies é indicativa de estádios sucessionais avançados (Budowski 1963). Nas descrições fisisionômicas da caatinga e do cerrado, os autores não se têm referido a trepadeiras, fato que leva a inferir que essa forma de crescimento não tem importância na caracterização fisionômica daqueles tipos de vegetação. Também não observamos, em nossas excursões ao campo, sua ocorrência em vegetações perturbadas de caatinga ou de cerrado. Como não há, na literatura especializada, menção da ocorrência de trepadeiras em vegetações perturbadas ou conservadas de caatinga ou de cerrado, não se pode afirmar que sua grande abundância no carrasco seja indicativa de perturbação de vegetação de caatinga ou de cerrado eventualmente preexistente e que tivesse originado o carrasco. Portanto, a ocorrência de trepadeiras, abundantes em número e espécies, distingue o carraseo da caatinga e do cerrado. Considerando exclusivamente a abundância de trepadeiras, o carrasco poderia estar relacionado com a floresta pluvial da encosta atlântica no sul do Brasil, que se caracteriza por apresentar grande riqueża de espécies trepadeiras, principalmente lenhosas (Klein 1980). Porém, as condições climáticas do carrasco são muito diferentes das ocorrentes na encosta atlântica no sul do Brasil. Portanto, a grande abundância de trepadeiras lenhosas distingue o carrasco do cerradão e da caatinga, porém não o distingue da capoeira.

Diâmetro basal do caule - Jaburuna apresentou $36,9 \%$ de suas plantas com 3 a $6 \mathrm{~cm}$ diâm. 
Tabela 2. Densidade (D) e área basal (G) por parcela e altura média na vegetação do carrasco em quatro localidades do planalto da Ibiapaba. Valores seguidos por letras iguais não foram estatisticamente diferentes pelo teste de Scheffé ( $\mathrm{p} \leq 0,01$; dp=desvio padrão)

\begin{tabular}{l|c|c|c}
\hline \multirow{2}{*}{ Localidades } & $\mathrm{D}\left(\mathrm{ind} / 100 \mathrm{~m}^{2}\right)$ & $\mathrm{G}\left(\mathrm{m}^{2} / 100 \mathrm{~m}^{2}\right)$ & Altura $(\mathrm{m})$ \\
\cline { 2 - 4 } & média $\pm \mathrm{dp}$ & média $\pm \mathrm{dp}$ & média $\pm \mathrm{dp}$ \\
\hline Jaburuna & $45 \pm 11^{\mathrm{a}}$ & $0,19 \pm 0,05^{\mathrm{a}}$ & $3,67 \pm 1,20^{\mathrm{a}}$ \\
Baixa Fria (1) & $59 \pm 20^{\mathrm{b}}$ & $0,14 \pm 0,06^{\mathrm{b}}$ & $3,84 \pm 1,33^{\mathrm{b}}$ \\
Carrasco (1) & $57 \pm 18^{\mathrm{b}}$ & $0,27 \pm 0,08^{\mathrm{c}}$ & $5,38 \pm 1,93^{\mathrm{c}}$ \\
Estrondo (1) & $66 \pm 14^{\mathrm{b}}$ & $0,20 \pm 0,07^{\mathrm{a}}$ & $5,31 \pm 1,63^{\mathrm{c}}$ \\
\hline
\end{tabular}

(1) Fonte: Araújo (1992)

do caule no nível do solo. Baixa Fria, Carrasco e Estrondo apresentaram $78 \%, 61,7 \%$ e $72,1 \%$ dos indivíduos com aquele tamanho (Fig. 2). A maior percentagem de diâmetros maiores em Jaburuna contribuiu para que a área basal fosse maior que a em Baixa Fria, que apresentou maior densidade (Tab. 2, Fig. 2). As quatro amostras de carrasco apresentaram mais de $88 \%$ de suas plantas com diâmetro inferior a $12 \mathrm{~cm}$, confirmando o predomínio de caules finos, realçado por Andrade-Lima (1978). Diâmetros pequenos e ausência de grandes diâmetros são alguns dos indicativos de estádios iniciais de sucessão secundária em florestas tropicais (Budowski 1963). No carrasco, os diâmetros foram pequenos e similares, de modo semelhante ao esperado numa capoeira. Considerando exclusivamente a distribuição de diâ-
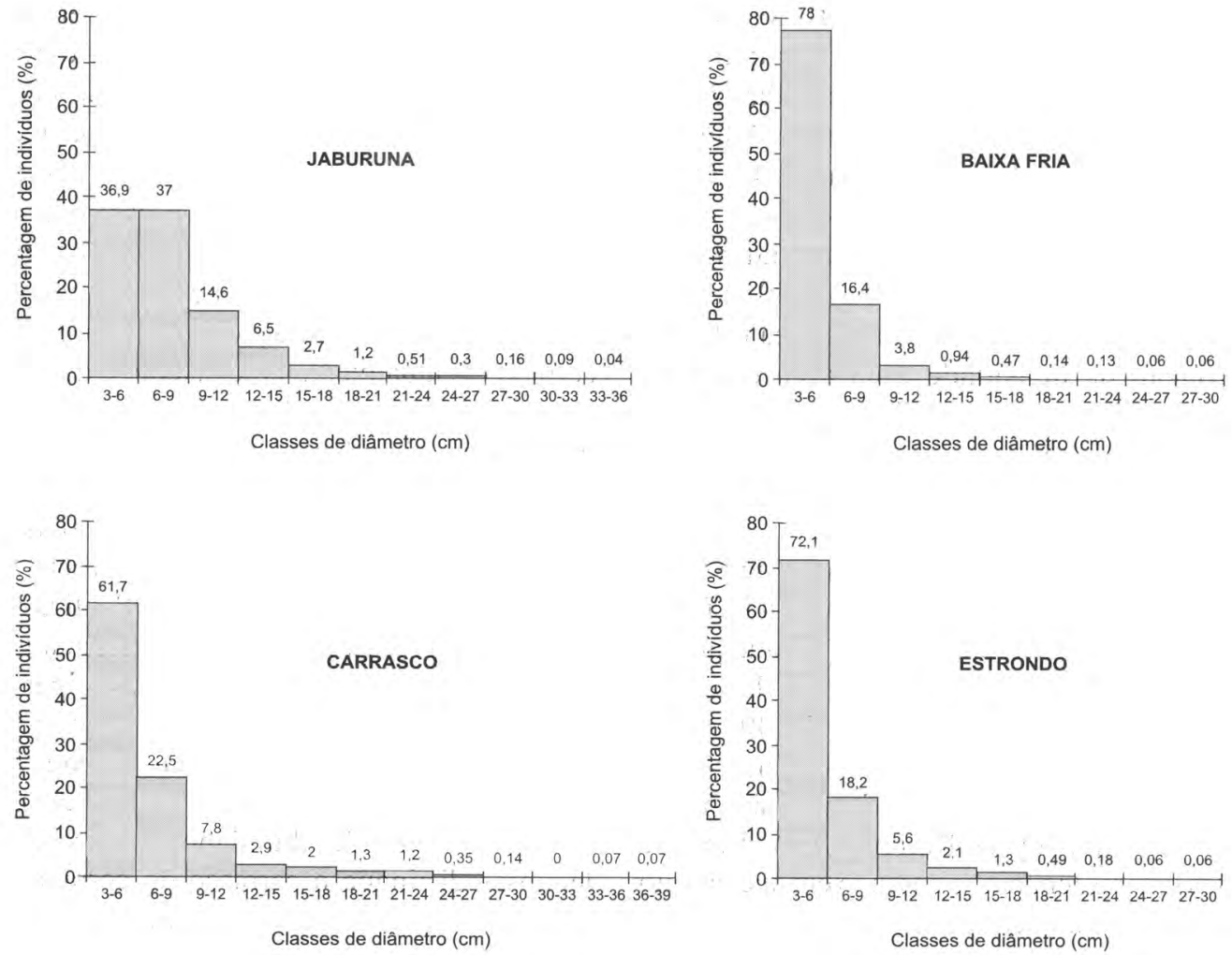

Figura 2. Distribuições de diâmetro do caule de arbustos e árvores, medido no nível do solo, na vegetação de carrasco em quatro localidades do planalto da Ibiapaba, CE 
metro, o carrasco apresentaria características de floresta perturbada, mas, na capoeira, a forma de crescimento predominante é a árvore, enquanto no carrasco foi o arbusto. Portanto, os diâmetros pequenos e similares encontrados no carrasco poderiam ser uma característica de formação vegetal predominantemente arbustiva, de caules finos, em que a pequena percentagem de diâmetros acima de $12 \mathrm{~cm}$ (Fig. 2) decorreria da presença de árvores esparsas.

Altura - A altura vertical média do componente arbóreo-arbustivo em Jaburuna foi de $3,67 \mathrm{~m}$. Comparado às amostras estudadas por Araújo et al. (1998b), o carrasco em Jaburuna apresentou a menor altura vertical média (Tab. 2). Em Jaburuna, $92 \%$ das plantas apresentaram alturas verticais de até $5 \mathrm{~m}$, enquanto, em Baixa Fria, Carrasco e Estrondo, $86,4 \%, 52,5 \%$ e $57,3 \%$ das plantas apresentaram até $5 \mathrm{~m}$ de altura vertical (Fig. 3). As amostras de carrasco em Jaburuna e Baixà Fria
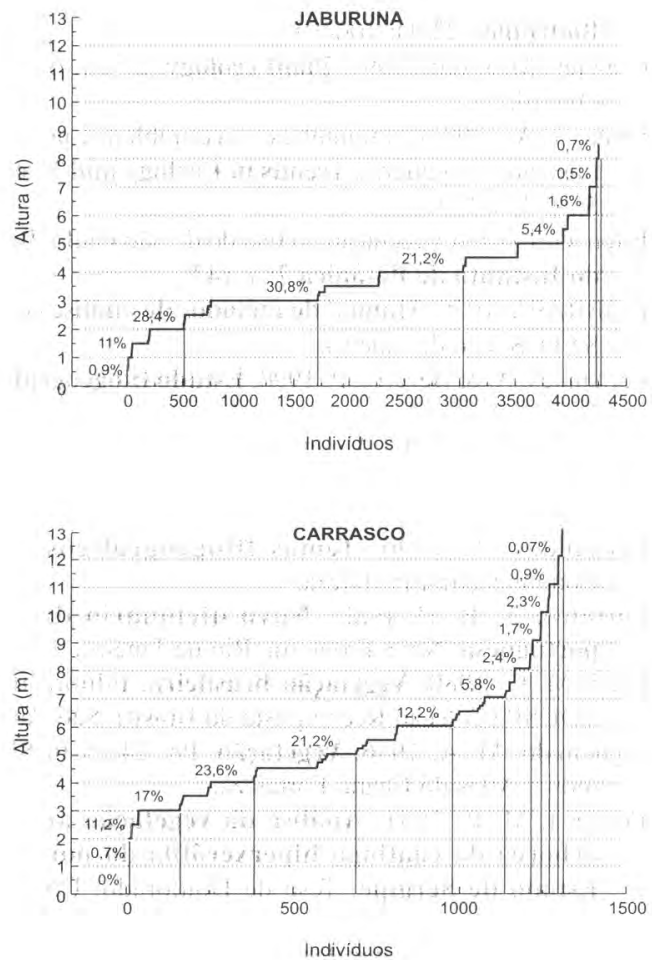

apresentaram as plantas mais baixas e as de Carrasco e Estrondo, as mais altas (Tab. 2, Fig. 3). Apenas $0,1 \%, 0,1 \%, 7,4 \%$ e $6,0 \%$ das plantas em Jaburuna, Baixa Fria, Carrasco e Estrondo, respectivamente, apresentaram alturas acima de 8m (Fig. 3). O predomínio de alturas pequenas indica a predominância de plantas microfanerofíticas (Raunkiär 1934) no carrasco. Em nenhuma das amostras comparadas, a linha de alturas do diagrama de rol formou um patamar longo, que pudesse indicar a ocorrência de um estrato característico na vegetação (Fig. 3). Ao contrário, a curva formou vários degraus curtos, apresentando-se inclinada, principalmente na porção superior. Isso mostra que as copas dos arbustos e árvores do carrasco ocorrem espalhadas em todo o espaço vertical da vegetação. Disso resulta uma fisionomia compacta, maciça, em que parece haver um único estrato, predominantemente microfanerofítico. Esses resultados confirmam a descrição feita por Andrade-Lima (1978),
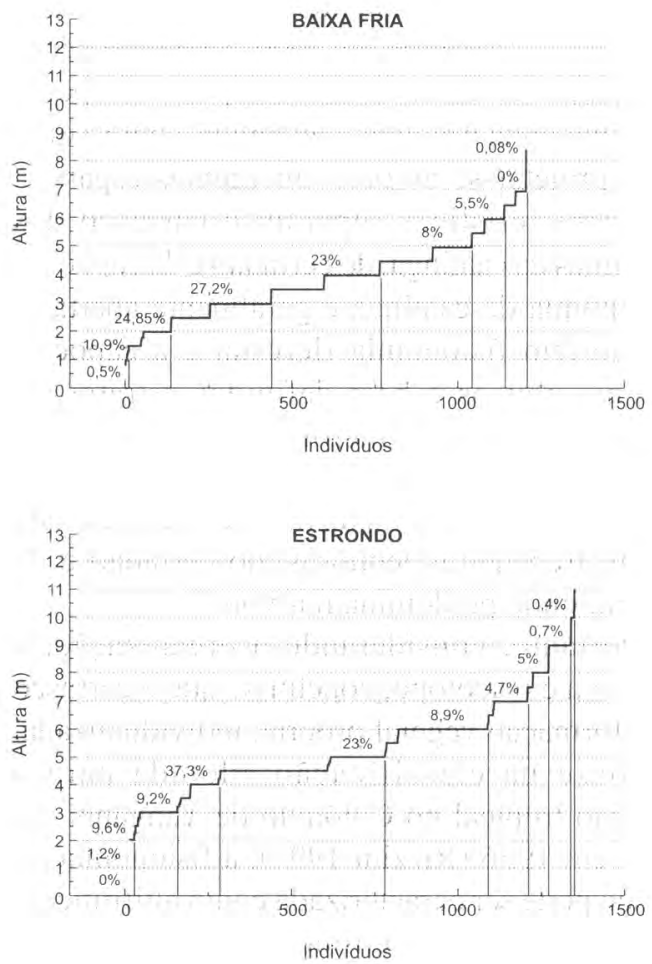

Figura 3. Diagrama de rol e distribuição de altura da vegetação de carrasco em quatro localidades do planalto da Ibiapaba, CE 
que distinguiu fisionomicamente o carrasco da caatinga pela sua maior densidade, uni-estratificação e menor espessura do caule das plantas arbustivas e arbóreas. O final da linha de altura nos diagramas de rol (Fig. 3) mostra tendência ascendente fortemente oblíqua a quase vertical, como em Carrasco. Essa forte inclinação positiva da curva no segmento das alturas maiores indica que a vegetação do carrasco não forma um dossel regular, como um telhado horizontal, mas que os indivíduos mais altos têm alturas diferentes, resultando numa linha de perfil muito sinuosa. Indica também a ocorrência de árvores emergentes esparsas, que, em algumas amostras, como em Carrasco e Estrondo, podem ser mesofanerófitas (altura maior que 8m, Raunkiär 1934).

Poucos e bem definidos estratos são indicativos de estádios iniciais de sucessão secundária, enquanto a presença de vários estratos pouco definidos é indicativa de estádios sucessionais avançados em florestas tropicais (Budowski 1963). O carrasco não tem estratificação, as copas distribuem-se cerradamente e entrelaçadas por abundantes trepadeiras em todo o volume aéreo da vegetação lenhosa. O limite superior do perfil forma uma linha irregular e quebrada, sobre a qual podem projetar-se árvores emergentes esparsas. Essas características separam o carrasco das fisionomias da caatinga, do cerradão e da capoeira. A fisionomia da caatinga é geralmente aberta, o cerradão tem fisionomia florestal e a capoeira apresenta poucos e bem definidos estratos. $\mathrm{O}$ carrasco é vegetação microfanerofítica, em que predominam arbustos e as trepadeiras lenhosas são muito abundantes, sendo distinto da caatinga, que não tem trepadeiras lenhosas, do cerradão e da capoeira, onde predominam árvores.

Portanto, considerando a organização, a fisionomia e o ecótopo, conclui-se que o carrasco é uma formação vegetal própria, individualizada. Com base na classificação adotada para a vegetação tropical no Colóquio de Yanganbi, na África, em 1956 (Rizzini 1997), a fisionomia do carrasco pode ser caracterizada como altifruticeto (Rougerie 1988) caducifólio denso, com trepadeiras e árvores emergentes esparsas, um tipo de "fourré" ou "shrubland."

\section{Referências bibliográficas}

Andrade-Lima. D. de. 1978. Vegetação. Pp. 131-135. In R. C. Lins (ed.). Bacia do Parnaíba: aspectos fisiográficos. Instituto Joaquim Nabuco de Pesquisas Sociais (Série Estudos e Pesquisas, 9), Recife.

Andrade-Lima, D. de. 1981. The caatingas dominium. Revista Brasileira de Botânica 4(2): 149-153.

Araújo. F. S. 1992. Composição florística e fitossociologia da vegetação de carrasco, Novo Oriente-CE. Dissertação de Mestrado. Universidade Federal Rural de Pernambuco, Recife.

Araújo, F. S.: Sampaio, E. V. S. B.; Figueiredo, M. A.: Rodal, M. J. N. \& Fernandes. A. G. 1998a. Composição florística da vegetação de carrasco, Novo Oriente, CE. Revista Brasileira de Botânica 21(2): 105-116.

Araúio. F. S.: Sampaio, E. V. S. B.; Rodal, M. J. N \& Figueiredo, M. A. 1998b. Organização comunitária do componente lenhoso de três áreas de carrasco em Novo Oriente - CE. Revista Brasileira de Biologia 58(1): 8595.

Bell. A. D. 1991. Plant form. An illustrated guide to flowering plant morphology. Oxford University Press. Oxford.

Budowski. G. 1963. Forest succession in tropical lowlands. Turrialba 13(1): 42-44.

Bullock. S. H. 1990. Abundance and allometry of vines and self-supporting plants in a tropical deciduous forest. Biotropica 22(1): 106-109.

Crawley. M. J. (ed.) 1997. Plant ecology. $2^{\text {nd }}$ ed. Blackwell. Oxford.

Drake. J .A. 1990. Communities as assembled structures: do rules govern pattern? Trends in Ecology and Evolution 5(5): $1.59-164$.

Eiten. G. 1970. A vegetação do Estado de São Paulo. Boletim do Instituto de Botânica 7: 1-147.

EMBRAPA. 1979. Manual de métodos de análises de solo. SNLCS. Rio de Janeiro.

Fernandes. A. \& Bezerra, P. 1990. Estudo fitogeográfico do Brasil. Stylus Comunicações, Fortaleza.

Fernandes, A. G. 1982. Vegetação do Piauí. Pp. 313-318. In Anais do XXXII Congresso Nacional de Botânica, Teresina 1981. Sociedade Botânica do Brasil, Teresina.

Fernandes, A. 1990. Temas fitogeográficos. Stylus Comunicaçōes, Fortaleza.

Ferreira, A. B. H. (s.d.) Novo dicionário da língua portuguesa. Nova Fronteira, Rio de Janeiro.

Ferri, M. G. 1980. Vegetação brasileira. Editora Itatiaia/ EDUSP (Coleção Reconquista do Brasil), São Paulo.

Figueiredo, M. A. 1986. Vegetação. Pp. 24-25 In SUDEC (eds.). Atlas do Ceará. Fortaleza.

Fonseca. M. R. 1991. Análise da vegetação arbustivoarbórea da caatinga hiperxerófila do noroeste do Estado de Sergipe. Tese de Doutorado. UNICAMP. Campinas.

FUNCEME. 1995. Dados de pluviometria por faixa de anos - Estado do Ceará. Departamento de Apoio Tecnológico (DETEC). Fortaleza. 
Furley. P.A.\& Ratter J. A. 1988. Soil resources and plant communities of central Brazilian cerrado and their development. Journal of Biogeography 15(1): 97-108.

Goedert. W. J. 1986. Solos dos cerrados; tecnologias e estratégias de manejo. (eds.) EMBRAPA-CPAC, Nobel, Brasíliat

Gomes. M. A. F. 1979. Padrões de caatinga nos Cariris Velhos, Paraíba. Dissertação de Mestrado. UFPE, Recife.

Hallé. F.: Oldeman, R. A. A. \& Tomlinson, P. B. 1978 Tropical trees and forests: an architectural analysis. Springer-Verlag, Berlin.

Jacomine. P. K. T.; Almeida, J. C. \& Medeiros, L. A. R. 1973. Levantamento exploratório-reconhecimento de solos do Estado do Ceará. v. I. SUDENE (Boletim Técnico 28). Recife.

Jacomine. P. K. T.; Cavalcanti, A. C.; Silva, F. B. R.: Montenegro, J. O.; Formiga, R. A.; Burgos, N. \& MeloFilho. H. F. R. 1979. Levantamento exploratórioreconhecimento da margen direita do rio São Francisco, Estado da Bahia. v. II. SUDENE (Boletim Técnico 52). Recife.

Klein, R. M. 1980, Ecologia da flora e vegetação do vale do latajaí. Sellowia 32: 165-389.

Lins, R. C. 1978. Bacia do Parnaíba: aspectos fisiográficos. Instituto Joaquim Nabuco de Pesquisas Sociais (Série Estudos e Pesquisas 9), Recife.

Löfgren. A, 1898. Ensaio para a distribuição dos vegetaes nos diversos grupos floristicos no Estado de São Paulo. Boletim da Comissão Geographica e Geológica de São Paulo 11: 50p.

Martins. F, R. 1990. Atributos de comunidades vegetais. Quid 9(1/2): 12-17.

Martins. F. R. 1991. Estrutura de uma floresta mesófila. Editora da UNICAMP (Série Teses). Campinas.

Mueller-Dombois, D. \& Ellenberg, H. 1974. Aims and methods of vegetation ecology. John Wiley \& Sons, New York.

Oldeman. R. A. A. 1979. Quelques aspects quantifiables de l'arborigenèse et de la sylvigenèse. Oecologia Plantarum 14(3): 289-3I2.

Oldeman. R. A. A. 1991. Forests. Elements of sylvology. Springer-Verlag, Berlin.

Raunkiaer. C. 1934. The life forms of plants and statistical plant geography. Being the collected papers of $C$. Raunkiaer. Clarendon Press, Oxford.

Reis. A.C. de S. 1976. Clima da caatinga. Anais da Academia Brasileira de Ciências 42: 325-335.
Rizzini, C. T. 1997. Tratado de fitogeografia do Brasil. $2^{a}$ ed. Âmbito Cultural Edições Ltda., Rio de Janeiro.

Rodal. M. J. N. 1992. Fitossociologia da vegetação arbustivo-arbórea em quatro áreas de caatinga em Pernambuco. Tese de Doutorado. UNICAMP, Campinas.

Romariz, D. A. 1974. Aspectos da vegetação do Brasil. IBGE. Rio de Janeiro.

Rougerie. G. 1988. Géographie de la biosphère. Armand Colin Editeur. Paris.

Sampaio, E. V.S. B. 1995. Overview of the Brazilian caatinga. Pp. 35-63. In S. H. Bullock; H. A . Mooney \& E. Medina (eds.), Seasonally dry tropical forests. University Press. Cambridge.

Sampaio, E. V. S. B. 1996. Fitossociologia. Pp. 203-230. In E. V. S. B. Sampaio; S. J. Mayo \& M. R. V. Barbosa (eds.). Pesquisa botânica nordestina: progresso e perspectivas. Sociedade Botânica do Brasil / Seção Regional de Pernambuco, Recife.

Shepherd. G. J. 1995. FITOPAC 1. Manual do usuário. Departamento de Botânica, UNICAMP, Campinas.

Shimwell. D. W. 1971. Description and classification of vegetation. Sidgwick \& Jackson, London.

Souza. M. J. N. 1988. Contribuição ao estudo das unidades morfo-estruturais do Estado do Ceará. Revista de Geologia 1(1): 73-91.

SUDEC. 1980. Levantamento de reconhecimento semidetalhado dos solos de região natural da Ibiapaba. SUDEC. Fortaleza.

SUDENE. 1990. Dados pluviométricos mensais do Nordeste: v.1 - Ceará. SUDENE (Série Pluviométrica 3). Fortaleza.

UNESCO. 1979. Écosystèmes florestiers tropicaux. UNESCO. Recherches sur les Resources Naturelles 14. Paris.

Vester. H. F. M. \& Cleef, A. M. 1998. Tree architecture and secondary tropical rain forest development. A case study in Araracuara. Colombiam Amazonia. Flora 193(1): 75-97.

Weiher. E. \& Keddy, P. A. 1995. Assembly rules, null models, and trait dispersion: new questions from old patterns. Oikos 74(1) 159-164.

Weiher, E.: Paul-Clarke, G. D. \& Keddy, P. A. 1998. Community assembly rules, morphological dispersion, and the coexistence of plant species. Oikos 81(2): 309 322 .

Wilkinson. L. 1992. SYSTAT: The system for statistics. SYSTAT Inc., Evanston.

Zar, J. H. 1984. Biostatistical analysis. $2^{a}$ ed. Prentice-Hall. Inc.. New Jersey. 